\title{
In Reply: Similarities between parasternal intercostal nerve block and subpectoral interfascial plane block
}

\author{
Yuichi Ohgoshi $^{1} \cdot \operatorname{Kentaro}$ Ino $^{1} \cdot$ Masakazu Matsukawa $^{1}$
}

Received: 7 February 2017 / Accepted: 4 April 2017 / Published online: 18 April 2017

(C) Japanese Society of Anesthesiologists 2017

To the Editor:

We thank Drs. Ueshima and Otake [1] for raising a concern that the parasternal intercostal nerve (PSI) block [2] and the subpectoral interfascial plane (SIP) block [3] are similar. The SIP block was carried out to relieve pain from a sternal fracture and the needle was injected $2 \mathrm{~cm}$ lateral to the sternal edge. In contrast, the PSI block was tested when a patient underwent mastectomy for breast cancer and therefore the needle entry point was as close to the sternum as possible to avoid tumor puncture. As such, these two methods were not the same. In addition, we had already submitted out paper for publication [2] when the paper by Raza et al. [3] was published. As a result, two different names were used for similar blocks, which we will leave open for discussion. Furthermore, we demonstrated an important finding in that local anesthetics spread over the adjacent intercostal space. Based on these facts, we think that the paper by Raza et al. and our paper are both noteworthy publications.

\section{References}

1. Ueshima H, Otake H. Similarities between parasternal intercostal nerve block and subpectoral interfascial plane block. J Anesth. 2017. doi:10.1007/s00540-016-2302-2.

2. Ohgoshi Y, Ino K, Matsukawa M. Ultrasound-guided parasternal intercostal nerve block. J Anesth. 2016;30:916.

3. Raza I, Narayanan M, Venkataraju A, Ciocarlan A. Bilateral subpectoral interfascial plane catheters for analgesia for sternal fractures: a case report. Reg Anesth Pain Med. 2016;41:607-9.

This reply refers to the article available at doi:10.1007/s00540016-2302-2.

Yuichi Ohgoshi

ohgoshi22@gmail.com

1 Department of Anesthesiology, International University

of Health and Welfare Mita Hospital, 1-4-3 Mita, Minato-ku,

Tokyo 108-8329, Japan 